\title{
Rethinking Laboratorio Experimental Towards a Methodological Transition
}

\author{
Diego Munguía Molina \\ Instituto Tecnológico de Costa Rica, \\ Centro Académico de Alajuela, \\ dmunguia@itcr.ac.cr \\ and \\ Jaime Gutiérrez Alfaro \\ Instituto Tecnológico de Costa Rica, \\ Centro Académico de Alajuela, \\ jgutierrez@itcr.ac.cr \\ and \\ Aurelio Sanabria Rodríguez \\ Instituto Tecnológico de Costa Rica, \\ Centro Académico de Alajuela, \\ ausanabria@itcr.ac.cr
}

\begin{abstract}
In 2012 the Instituto Tecnológico de Costa Rica opened the Computer Engineering program at the recently created Centro Académico de Alajuela. At that time there were neither research space nor resources available for undergraduate students to practice problem solving by applying theoretical concepts to real life problems. The Laboratorio Experimental was proposed in mid 2013 as a research initiative where students and faculty could engage together in projects powered by low cost open hardware and free software. This article shares the experiences learned by the proponents of the lab and a detailed explanation of the projects, also describes the results of students academic experience.
\end{abstract}

Keywords: engineering education, undergraduate research, student projects, research experience, educational experiences.

\section{Introduction}

Instituto Tecnológico de Costa Rica (TEC) is a public university in Costa Rica focused on Science and Technology. Established in 1971, it has been operating since 1977 in Cartago, San José and San Carlos. Recently, TEC is undergoing a growing phase by adding more campuses, called Centros Académicos (Academic Centers).

The Computer Engineering (IC) Progran ${ }^{1}$ is offered by academic units associated to the School of Computer Engineering in all five campuses, being the academic centers with the last three to start the program being: Centro Académico de Alajuela(2012), Centro académico de San Jose(2013) and Centro académico de Limón(2014).

This program consists of a series of mandatory and optional courses encompassing specific areas of different computing disciplines, such as computer science, computer systems architecture, and software engineer-

\footnotetext{
${ }^{1}$ Even though the program name is Computer Engineering its courses cover different areas including computer systems architecture, computer science and software engineering. From this point on, we'll use the acronym "IC" —in spanish- to keep the reader aware of this difference.
} 
ing. In addition, sports, cultural activities, mathematics, social sciences, philosophy and entrepreneurship courses complement the curriculum. The program concludes with the participation of students in a real software engineering project and a six-month supervised internship in a public, non-governmental or private institution.

The academic center in the town of Alajuela (CAA) started operating without having the minimal set of academic and administrative services provided in other campuses. Besides attending lectures and completing assignments, the absence of a broader offering of activities for students was evident since the first year. Although student enrollment has not been affected by this -40 to 80 new students are admitted each year-, high career dropout rates represent an issue. By the end of 2013, access to Student Services began to improve with the addition of personnel for social work and psycho-educational support. Also the Admission and Registration Department joined the following year.

In 2014, most of the academic units implementing the IC Program underwent an accreditation process with the Sistema Nacional de Acreditación para la Educación Superior ${ }^{2}$ (SINAES). This process highlighted among other things, the necessity to improve students' writing and speaking skills, their abilities for teamwork and the application of research techniques and methodologies. SINAES findings show correspondence with Radermacher and Walia 1 manifestations, who showed -from the employer industry perspective- the lack of certain skills in graduate students from computer-related disciplines. This study highlights the skills that are to be reinforced mostly in university education: written and oral communication, project administration, use and selection of software tools and quality assurance processes.

Traditionally, TEC's approach to keep students acquiring skills beyond the classroom has been to include them in research and development projects, funded by the institution and directed by faculty. The inception of the Laboratorio experimental (LabExp) was motivated by the interest to involve undergraduate students in academic activities to complement their education, and explore different mechanisms to improve the development of skills not comprehended explicitly in the program's curriculum. Research, development and educational laboratories have been to a great extent, the spaces in which the students have found the opportunity to overcome those limitations [2]. During the past years the LabExp tested different forms of academic activities related to areas such as research methodologies, software development process, teamwork, and oral and written communication.

This article shares the experiences learned by the proponents of the LabExp since its inception. Related work that conceptually supports the working proposal of the LabExp are presented in the next section. The third part of the paper includes LabExp's objectives, cross-sectional tasks and a detailed explanation of general methodological decisions. Following sections include an evaluation of the laboratory's impact, conclusions and future work.

\section{Related Work}

An important transition in computational technology was observed in the 70s, going from mini-computers to micro-computers and bringing about new educational possibilities that up to then had not been viable. The educational environments of that time changed from being spaces containing small numbers of hardware used under restricted time conditions, to places with several computers widely used by the students [3] [4]. Thus, Computing Engineering, which in the beginning used no laboratories for academic education (or at least not in the same way as other disciplines, like physics or chemistry) could then offer the students spaces to start experimenting with the machines in a more generalized way, and give them the opportunity to strengthen the theoretical concepts of the discipline [2].

In the following decades, the increase of performance of computational equipment enabled the creation of virtual and remote laboratories, added to on-site labs. Ma and Nickerson 5 published a literature review on this type of laboratories, underlining the fact that more than technology, it is the contact between classmates and professors that has an effect on student education. They also pointed out that the economic cost of setting up a laboratory is an aspect to be regarded when determining whether to carry out in-person, virtual or remote activities.

The cost of the necessary tools for technology development (design, modelling, prototyping and fabrication) fell considerably by the end of the 90 s, giving rise to the creation of personal fabrication laboratories (Fab Labs), Hackerspaces and Makerspaces. Incorporating these spaces into formal and informal models of education offered great opportunities, Mikhak and Gershenfeld in 2002 6] compared them to the impact of the development of personal computing in the 70s. Before 2015, access to these spaces was not openly available in Costa Rica, as it was in the USA and Europe either with Fab Labs, Hackerspaces or Makerspaces.

One of the first Fab Labs was created in Costa Rica in 2002 at TEC, its work focused on developing lowcost technological solutions for low-income, rural areas of the country. The work was carried out engaging

${ }^{2}$ http://www.sinaes.ac.cr 
undergraduate students with project development [7] and the activities called "Campamentos de Aprendizaje por Construcción" -bootcamps for learning by building-, where students carried out educational dynamics with children for learning basic concepts of robotics [8. In 2015, a new Fab Lab was opened at the "Centro de Investigación para la Innovación", in Universidad Veritas? and also at "La Inventoría" "4 a Makerspace which is part of the Fundación Costa Rica para la Innovación. The Costa Rican National Science, Technology and Innovation Plan (with a 5 year time frame 2015-2021), includes innitiatives to incentivate the creation of Personal Fabrication Laboratories and a increasing number of prototypes created in maker spaces is expected 9 .

Access to computing laboratories allows professors to design specific educational dynamics to positively complement the contents of the courses of the Computer Science and Engineering programs [10] [11] [12. Generally speaking, fabrication spaces (FabLabs, Hackerspace or Makerspace) allow the development of technical and technological skills through informal teaching and learning methodologies [13] [14].

As described by Bailey et al [15, the creation of spaces where undergraduate students can participate in research processes is a task involving many details. They point out, for example, the relevance of project design to assign adequate workloads for students according to their capabilities; setting up a productive research environment and support and commitment from the administrative body of the university where the work is being performed.

The Applied Computing Technology Laboratory, ACT Lab, created by Way [16] at Villanova University is a successful example of involving undergraduate students in collaborative research processes with members of the university community and other students. In this Laboratory, the interaction among members is virtual, there is no physical space available; instead, the research processes are coordinated in a web page. The ACT Lab has enabled the development of an important number of projects on varied topics, i.e. nanotechnology, high performance computing or computing sciences education.

Similarly, the Department of Computing Sciences of West Georgia University obtained positive results incorporating undergraduate students into research processes. According to Rahman [17, this university was not characterized by its research processes and has no infrastructure for this purpose; however, after 3 years working with undergraduate students, they point out that the process has improved the students' skills for programming, problem solving analysis and written and oral communication.

Megalingam and Rajendran [18] report that the Department of Electronics and Communications at the University of Amerita in India also obtained positive results regarding student education after incorporating them into research processes. They consider that publications resulting from the process allow students to participate in international conferences and coming into contact with the industry and other university research laboratories. They also highlight that the process as such also pose important research challenges for faculty.

Student engagement has been used as a reference for undestanding their experience as learners. Research done by Butler, Sinclair et al meta-analysing data from major engagement surveys, like North American National Survey of Student Engagement (NSSE) and the Australian University Experience Survey (UES), indicated that students from areas related to Information, Communication and Technology (ICT) rates lower than average. Despite critizing the surveys results, they recommend computer science programs incorporate teaching and learning activities to engage and support students throughout their undergraduate studies, this will improve students recruiting and retention [19]. They also notice a shift away from the traditional lecture activity of one-way delivery of large volumes of content and the in-class experience, as academics seek ways to involve students in active and collaborative learning experiences. 20. As further work, they point out more qualitative data is required in order to better understand the ICTs students experience [21].

In their paper Peters et al describe three types of experiences of creation, systematic problem solving and creating knowledge for others when students engage in learning activities other than lectures. With such activities students experience empowerment to do things or create knowledge, and learn methods and tools that enable them to systematically approach the process of creating. The experience of creating for others furthermore enriches the experience as creation now is not experienced as an end in itself [22].

\section{Laboratorio Experimental}

During the second year of teaching courses of the IC program at the Centro Académico de Alajuela (2013), the need to create spaces for students to involve themselves in academic activities not considered in the curriculum was evident. At the other TEC campuses, these spaces are provided in the form of research and extension projects, allowing students to complement their learning while contributing with specific tasks under the supervision of a professor.

\footnotetext{
${ }^{3}$ https://www.fablabs.io/fablabveritas

${ }^{4}$ http://inventoria.org/
} 
Additionally, during the aforementioned process of accreditation conducted in 2013, a document called Commitment for Improvements was produced. The commitment included aspects to be improved in the program, specifically: student oral and writing skills, teamwork and technical and methodological capabilities for research. The inputs provided by this document provided an important guide to decide how to focus LabExp's efforts.

The need for academic spaces and improvements towards accreditation led us to propose the creation of the Laboratorio Experimental de Tecnologías Computacionales (LabExp). It was approved by the Technical Committee of the Centro de Investigaciones en Computación (CIC) $)^{5}$ of the School of Computer Engineering. The LabExp has two cross-sectional tasks: (a) provide support to IC courses, mainly related to computer architecture, compilers and interpreters, operating systems and networks; and (b) strengthen research and extension. In addition the following objectives:

1. Offer a space for the undertaking of practical work in support of the IC program.

2. Establish a creative environment conducive to the development of proposals for research and extension projects.

3. Develop academic projects to promote adequate involvement with the community.

4. Create a space which can later be replicated in other campuses where the School of Computer Engineering is present.

The LabExp started working administratively by the end of 2013, defining methodological guidelines and topics of interest, both aspects finely interweaved. Because of the interest in involving undergraduate students in academic activities to complement their education, one of the Laboratory guidelines was to use Free/Open Software and Hardware, validated in the educational opportunity made available with these licensing models [23. Besides, given that TEC is a public university it is important to develop solutions that are always available to society. The areas of interest of the Laboratory are Free Software, Free Culture and Open Data, the three of them defined accordingly with the guidelines of the Laboratory and the interest of the professors involved.

In the definition of the initial projects the level of advancement of the students was especially considered. By 2013, the majority of students were doing their first year, while a few of them were in their second year. Professors' specific interests and the needs of the university community and of the society were also taken into account. Work started with two projects: Buses, and Información Libre y Tecnología (ILT). By 2016, the project Buses shifted from having research assistants working on complex tasks to working with course students on simple specific course-related tasks; a new project called Bëküo was started and new students got involved in ILT as former ones finished their studies. All of these projects will be described in the following sections.

The overall coordination of the LabExp's work is performed by means of monthly meetings with the professors involved. An organizational structure was established for each project, including at least one professor as coordinator and a group of undergraduate students. Each project's specific tasks are established internally by the work groups during meetings where the professors set the goals for the students participating in the project. Overall follow-up of the assignments is carried out using software tools such as code repositories, wikis and task control and issue tracking applications. Additionally, as a way to introduce students to scientific writing, students keep work logs and blog posts are generated regularly reporting progress on the projects. Every post contains three mandatory sections: problem description, methodology and conclusions.

Regarding the cross-sectional task for providing support to program courses, low cost open hardware computing equipment was chosen to be used by course students. The procedures to acquire the essential equipment and tools for LabExp to operate started in 2014 (see Table 1). Arduino Kits and Raspberry Pi computers are being used in small assignments for the Data Structures and Computer Architecture courses with interesting preliminary results. The original idea for the LabExp included turning it into an open experimentation space -just like a Fabrication Space-, however it was postponed due to the lack of assignment of an appropriate and permanent physical space. Instead, efforts are now focused on the research projects. Demonstrating the cross-sectional task for strengthening research and extension, Free Cartography Workshops were imparted around the country during August of 2016 as part of a national celebration on Science and Technolgy promoted by the Costa Rican Ministry of Science, Technology and Telecommunications.

\footnotetext{
${ }^{5}$ Session 19-2013 of the Technical Committee of the Computing Research Center.
} 
Table 1: Laboratorio Experimental equipment Components Units Cost in USD

$\begin{array}{lcr}\text { Raspberry Pi } & 30 & \$ 1771 \\ \text { Arduino Kits } & 29 & \$ 3333 \\ \text { Digital Photographic Cameras } & 2 & \$ 417 \\ \text { Cell phones } & 2 & \$ 556 \\ \text { Digital tablets } & 2 & \$ 1325 \\ \text { Other components and material } & & \$ 1516 \\ \text { Total } & & \$ \mathbf{8 9 1 8}\end{array}$

\subsection{Projects}

\subsubsection{Información Libre y Tecnología (ILT)}

This project was conceived as a means to involve IC second year students with the common software development processes of Free Software and Open Source (FLOSS) communities, as well with research methodologies. The DIY Book Scanner community, founded by Daniel Reetz, creates inexpensive scanners for document digitalization 24. As a result of the link established with this community, Reetz donated a scanner to facilitate work on the development of Free Software to control the process of document digitalization.

Since Free Culture is one of the areas of interest of the Laboratory and considering that in a wide variety of scenarios access to texts and documents in digital format contributes to preserve knowledge as a world heritage, the team set the goal to promote free access to information and culture. Providing a digital version facilitates access to texts physically inaccessible, such as documents that are otherwise difficult to find or are located in distant libraries.

Starting with the technical challenge of building Free Software for document digitalization, throughout the first year the project focused efforts on giving support to the DIY Book Scanner community by creating installation and user manuals for the tools available at the moment. However, in the second year, based on the experience acquired, the team developed a proof of concept with the aim of analyzing new design and user interaction strategies with the software for document digitalization. During this process, the campus library became involved as a user, providing feedback on workflows, usability and additional needs.

During 2015, students developed the proof of concept into LibreScan ${ }^{6}$, which became a free and functional software option for text digitalization with low-cost scanners. At this point the software is being used by the campus library as a component of a software solution to aid students with visual disability (see figure 1). An academic paper 25] outlining project results was presented by the students in the Free Software Workshop of the International Free Software Forum held during July 2016, in Porto Alegre Brazil. During this workshop students attended multiple conferences in Spanish, English and Portuguese and communicated with Free software researchers in English and Spanish.

Considering that the team members were set to finish their studies by 2016 second semester, a new generation of three students, coursing their second year at the moment, were recruited to work in the project. This new generation was highly motivated but unwilling to work on non-technical tasks like scientific log writing, blog post writing and paper reading, presenting a significant engagement challenge. Introductory tasks were assigned to respond to the needs expressed by current users through an informal survey. By the end of the semester LibreScan installers for the Python Package Index (PyPI) and Debian based distributions were available and a few video tutorials are being produced.

Contacts have been made with the Mexican hackerspace Rancho Electrónico and the Paraguayan nongovernmental organization TEDIC -who own a DIYBookScanner- so that they carry out tests with this software. Regarding future work, from a technical point of view the proposal is to explore the processes related to the identification and correction of errors introduced by text recognition, a functionality that has not been integrated into LibreScan yet. Additionally, expand the utility of the software with tools that facilitate the use of digitalized books by people with visual disabilities, such as text-to-speech transformation.

\subsubsection{Buses}

This project was created with the aim of involving students in software development activities framed within a research project on open data. It seeks to give students experience on different software engineering processes, in this particular case, building software components to produce and consume open data about public transportation networks.

\footnotetext{
${ }^{6}$ http://labexperimental-siua.github.io/LibreScan/
} 


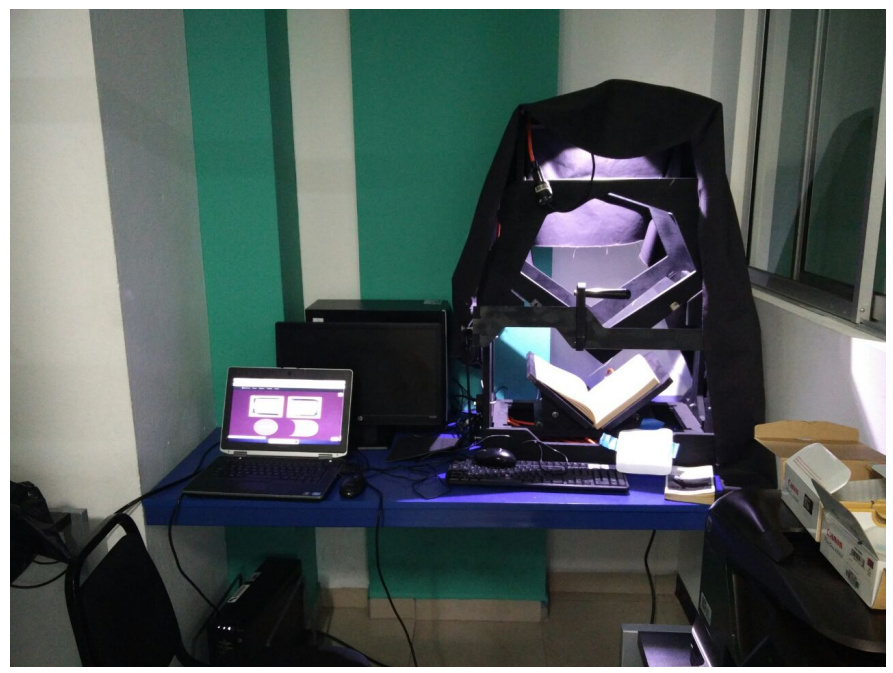

Figure 1: DIY Book Scanner in the university's library.

In 2014 we worked with a group of students in the evaluation of different tools for software development based on a set of requirements to create a mobile application that suggests to end users the different sections of public transportation they should take to move from point A to point B. Since the participating students had not taken the Software Requirements course at this stage, the requirements of the proof of concept were defined by the professor in charge based on the performance of similar applications and personal experience of project participants as users of public transportation. The methodology consisted of assigning the same evaluation and prototyping tasks to each individual student and then hold review sessions in groups where students discussed their findings and reported their evaluation of the different tools proposed by the professor.

During the second semester of 2014 and the first one of 2015 the team got reduced to a subset of the original group of students, the team executed a stage of user experience design and the development of a user interface prototype for mobile devices. During the second half of 2015 and summer 2015-2016, the project included two teams of students enrolled in the Software Engineering Project course in the development of software architecture, data modelling, application and prototypes of integration with open data repositories provided by the Consejo de Transporte Público de Costa Rica 7 - the government institution in charge of public transportation- and Open Street Map\$8

After these stages, the project got to a point where the experience accumulated was analyzed in retrospective and the outcome obtained was a set of functional and technical requirements. With these requirements it was possible to start a process of software development in which students with varying levels of knowledge and experience can get involved. There is a lot of potential in this final stage for students to obtain practical experience in the area of software engineering.

With these requirements available, a different approach was taken to involve students in the project. The course Software Engineering Project requires students to manage and develop a software engineering project. They are responsible for the proper completion of all the phases of a typical project, including requirements gathering, software design, software development, quality assurance and project management.

As of 2016, the Buses project started offering functional requirements to student teams enrolled in IC7841; the projects are scoped so they can be completed in the 16 weeks the semester lasts. On completion, projects are integrated into the architecture of the system and deployed in a virtualized server environment. So far, two teams have participated and both have succesfully completed their projects.

\subsubsection{Bëküo}

Bëküo was created with the goal of providing mechanisms to capture, edit and share geospatial data of humanitarian interest in the Costa Rican context. Three students are working on this project, one advanced student and two freshmen. A prior project was done during the summer 2015-2016 when a fire hydrant data mapping was held on the Alajuela City Central Area. With that experience the first semester work was focused on documenting the methodological best practices and tools for mapping. The results were shared on the Open Street Map Wik 9 and presented during outreach activities like: Open Data Day 2016 and the

\footnotetext{
${ }^{7}$ http://datos.ctp.go.cr/home

${ }^{8}$ http://www.openstreetmap.org

${ }^{9}$ https://wiki.openstreetmap.org/wiki/ES:Alajuela\#Hidrantes
} 
University vocational fair.

The next steps for the project are: a survey of mapping tools, creating a guide for fire hydrants mapping, definition of the data needed to map fire hydrants and modifying a data capture tool. The survey was carried out with a special emphasis on the rigorousness of the process, specifically the definition of the search criteria and the evaluation of the results. The intention of this approach was the strengthening of research skills. The fire hydrants mapping guide was was done based on prior experience and written in Spanish according to the expected audience, the final users of the tools. The corresponding OSM Wiki pag $\AA^{10}$ was also translated to Spanish.

Based on the 2008 National Law No 8641 "Declaratoria del Servicio de hidrantes como Servicio Público y Reforma de Leyes conexas" (Declaration of the Fire Hydrant Service as Public Service and Reform of Related Laws), a definition of fire hydrant data attributes and their possible valid values was done. This data model is going to be the base for the customization of selected tools for the processes of capturing, editing and sharing data. The OSMTracker ${ }^{11}$ tool was modified to include an additional layout that makes it easier to capture fire hydrants (and bus stops) data.

The undergoing work is to extend the capabilities of the selected mapping tool (OSMTracker) and create a server side service to automate validation of the gathered data based on our data schema for Costa Rican fire hydrants. Future work includes engaging users to help testing the tools as well as creating useful visualization options to motivate the users to contribute with Bëküo.

\subsection{Free Cartography Workshops}

As every year since 1986, the Costa Rican Ministry of Science, Technology and Telecommunications (MICITT) celebrates in August a month of activities aimed at promoting science and technology. In 2016, 6 different rural areas were selected to host workshops targeted to K-12 students. LabExp was invited to participate with two workshops about free cartography including topics like Open Data and Free Software.

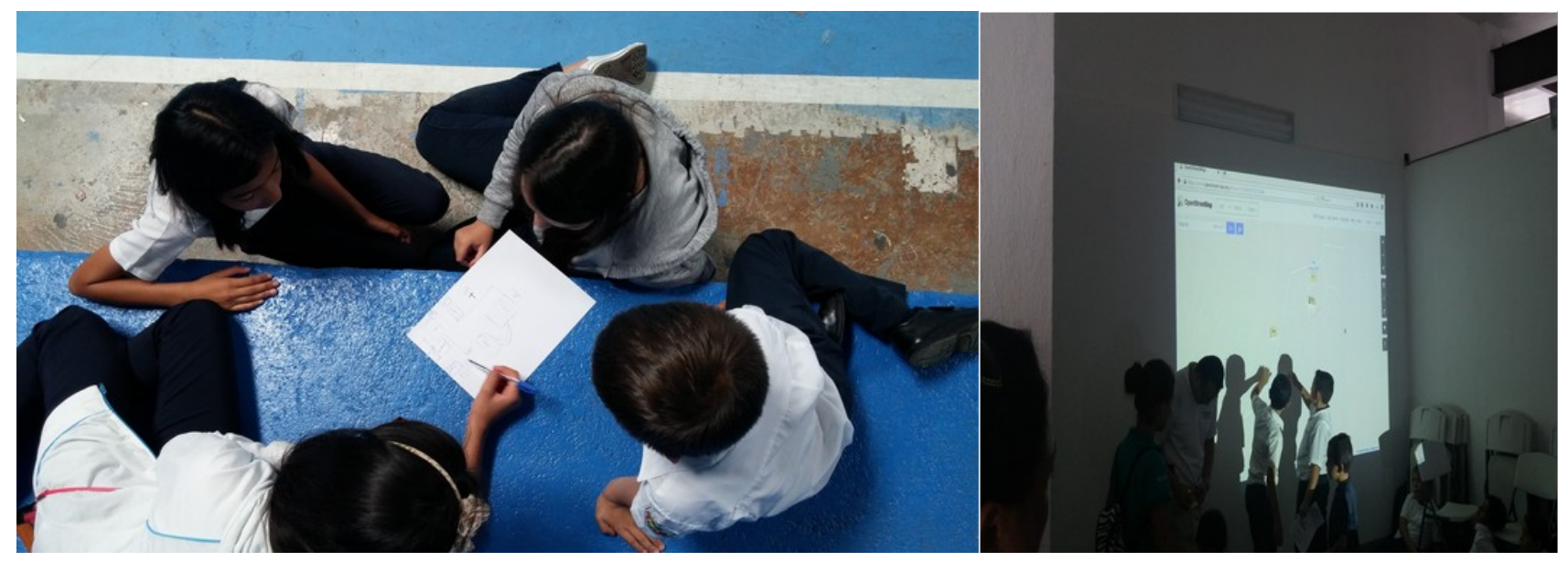

Figure 2: School students during the workshop . (a) Left. Data recollection. (b). Right. Collaborative map editing.

The overall experience was challenging because of complex logistics and the particularities of the locations. For example there was no guarantee that computer labs or a suitable Internet connection would be available. Workshops logistics was planned in a way no Internet access was required to participate. Also, to promote the engament of IC students, they were invited to participate as workshop facilitators. For each location, different teams of 2 professors and 9 students attended.

The Free Cartography Workshops (see figure 2 ) methodology was based on Louis-Julien de la Bouëre's presentation "OpenStreetmap for educational purposes!" 12 which focuses on working with children to introduce them to Open Street Maps concepts. The first activity called "Sharing knowledge" was a theoretical lecture where basic cartography concepts and definitions were explained such as maps, gps, points, traces, open data and free software; Ramm, Topf and Chilton's book on OSM was used as reference 26. The second part named "Improving maps" was the practical complement of the first activity. Recently explained cartography concepts were applied in a field exercise to develop skills for geospatial information gathering and collaborative map editing.

\footnotetext{
${ }^{10}$ https://wiki.openstreetmap.org/wiki/ES:Tag:emergency\%3Dfire_hydrant

${ }^{11} \mathrm{https}$ // github.com/nguillaumin/osmtracker-android

${ }^{12} \mathrm{https}$ ///prezi.com/fllotlpmrkpb/openstreetmap-workshops-with-children/
} 
The total attendance for the workshops was 1214 K-12 rural area students. A proportion of $23 \%$ of the IC program student population participated as facilitators. It's important to highlight that more than $50 \%$ of the female student population was involved -9 out of $15-$. The short two-day trips each week -instead of a one week long trip- turned out to be a key logistic aspect; because it allow students to participate minimizing absences to their courses. An open survey was conducted to every workshop facilitator aiming to better understand the experience from the undergraduate students point of view in terms of: engagement in the IC program, value of the educational experience and methodological recommendations for future workshops. The survey results will be presented in another paper.

\section{LabExp Assessment}

\subsection{Students Participation}

Table 2 describes the impact of the Laboratory in terms of university students involved in some way with LabExp. The column of students population considers the total number of active students -enrolled in a course - at the beginning of each semester from 2013 to 2016. The following columns show, respectively, the quantity of students participating as assistants in research projects; student that used the materials provided by the Laboratory for some course, students involved in cartography workshops and the coverage percentage.

Table 2: Impact of the Laboratorio Experimental in the students population

$\begin{array}{lccccc}\text { Year - Semester } & \begin{array}{c}\text { Student } \\ \text { population }\end{array} & \begin{array}{c}\text { Assistant Students in } \\ \text { research proyects }\end{array} & \begin{array}{c}\text { Students } \\ \text { in courses }\end{array} & \begin{array}{c}\text { Students } \\ \text { in Workshops }\end{array} & \text { Coverage \% } \\ 2013 \text { - II } & 92 & 4 & 0 & 0 & 4,35 \% \\ 2014 \text { - I } & 114 & 15 & 0 & 0 & 13,16 \% \\ 2014 \text { - II } & 101 & 6 & 0 & 0 & 5,94 \% \\ 2015 \text { - I } & 124 & 4 & 5 & 0 & 7,26 \% \\ 2015 \text { - II } & 117 & 6 & 45 & 0 & 43,59 \% \\ 2016 \text { - I } & 9 & 24 & 0 & 21,29 \% \\ 2016 \text { - II } & 155 & 6 & 23 & 33 & 43,66 \%\end{array}$

Participation in research projects has remained steady. The number of courses that takes advantage of the lab materials to offer educational dynamics to reinforce theorical concepts is still scarse (computer architecture, data structures and software engineering project). The number of students in courses using LabExp's material are dropping due to the periodical offer of courses. It's expected to keep these numbers in the order 30+ students per semester. Free Cartography Workshops added a new type of activity with less intensive involvement but open to more students.

\subsection{Skills Developed by Assistant Students}

Assistant students were interviewed to investigate about the skills they learned as participants of research and development projects.

Technical skills -also called hard skills- learned during the project included new software development tools, specific software tools, programming techniques and development process strategies. Soft skills are related to techniques for communicating ideas and disseminating project results and are divided in two types: (a) oral and/or written dissemination of results, including progress reports, technical documentation and project presentation to nontechnical audiences; (b) language skills required during research processes and problem solving, involvement with communities of developers and contact with users actively using the tools involved in the project.

Regarding hard skills, students reported using free operating systems (GNU/Linux Debian and Ubuntu) mainly for software development and distribution. Similarly, they used Open Source and Free licensed tools in a wide range of tasks such as text recognition, image management, version control, web and mobile development. Finally, the participants were involved with open data and free hardware projects, Open Street Map, Arduind ${ }^{13}$ and Raspberry $\mathrm{P}^{14}$ in particular.

As to soft skills, students indicated that they presented results to diverse audiences. They also reported to project coordinators through research logs documenting their daily individual work and progress. Logging tasks were performed informally, according to the student's preference. In addition, the results were presented to the general public using two main mechanisms: virtually, by means of digital media for the distribution

\footnotetext{
${ }^{13}$ http://ardino.cc

${ }^{14}$ https://www.raspberrypi.org/
} 
of technical manuals, user guides, error reporting and informative articles; and in person, by means of information stands in vocational fairs and community outreach activities. Also, written communication recorded heavy use of the English language, while Spanish was used to a lesser extent, in contrast to oral communication, where Spanish was often used.
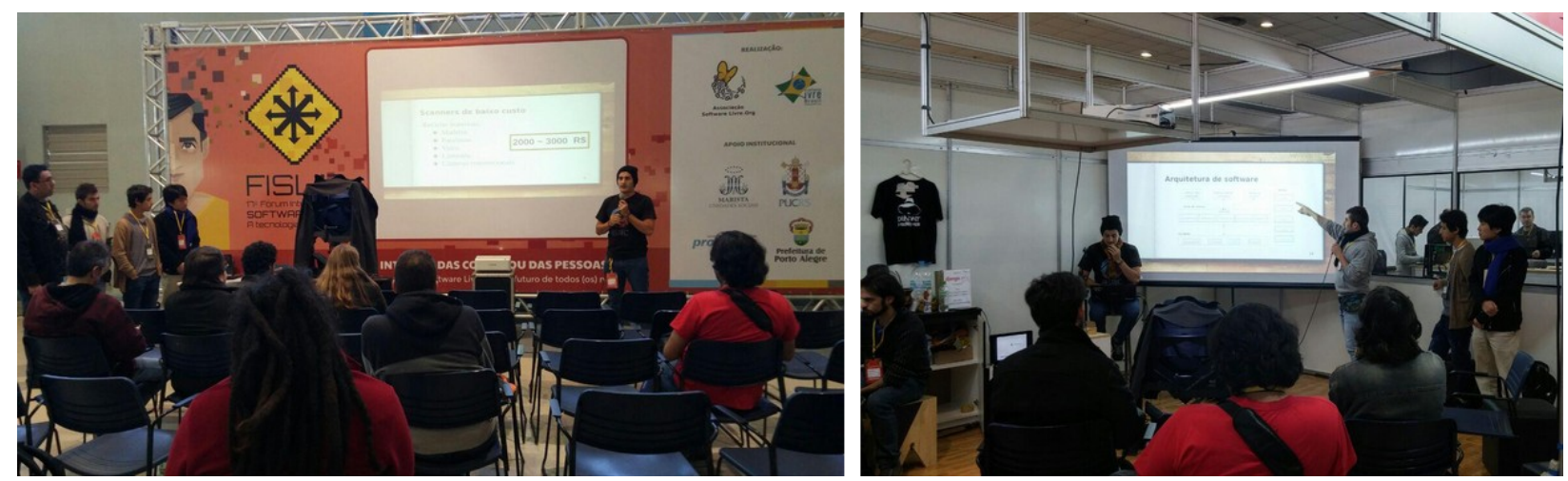

Figure 3: ILT Students presenting their work at the International Free Software Forum (FISL)

In broad terms, the results indicate that undergraduate students involved in LabExp's research projects improve their skills as follows: technical skills linked to solution designing (logic, syntax, semantics, abstraction capability); social skills, (writing, spelling, communication, analysis and collaborative team learning) and professional skills (acquaintance with working tools in practical conditions), as well as improved understanding of theoretical concepts through practice.

\subsection{Methodology Evaluation}

The approach of including students into research and development projects resulted in the projects briefly explained in previous sections: "Información Libre y Tecnología (ILT)", "Buses" and "Bëküo". LabExp has obtained positive results by following this approach. In spite of limitations in infrastructure, resource availability, experience and time; the project "ILT" completed a full life-cycle from inception to the production of publications and the presentation of results in an international forum [25]. As mentioned before, an evaluation applied to the participating students revealed improvements in teamwork, oral and written communications and the acquisition of international experience. The other projects, still in progress, have involved students in teamwork dynamics and situations where they have to present and explain aspects of the projects to an audience.

Eventhough the approach produced interesting positive results, participating faculty members have identified important shortcomings, being the most relevant the limited quantity of students that can be directly involved in a project. This limitation is mostly due to the demanding time investment requirements both for participating students and project directors, roughly comparable to the time required by a tutorship activity. Other shortcomings are more related to financial limitations.

Given this situation, LabExp has started transitioning its methodological approach, from long term involvement of students in projects to designing enriching educational experiences that can involve more students in a shorter timespan. These activities are more focused and specific, and require less commitment of students in the long term. Example activities include involving students as final users of proof-of-concept tools; involving students in data collection activities; involve students in extension activities as workshop facilitators; and, bringing projects' activities to the classroom as part of specific courses and lectures.

The "Free Cartography Workshops" was the first LabExp activity following this new approach of enriching educational experiences, yielding preliminary positive results in the development of soft skills and social involvement; however the analysis and publication of official results are still pending.

\section{Conclusions and future work}

After 3 years of work, the LabExp has its own physical space in which research and extension projects have been conducted with the involvement of undergraduate students. The LabExp also offers the professors low-cost computing equipment to design educational dynamics aimed at improving understanding of the theoretical concepts of the courses. The LabExp became the only research and extension space of the IC program at the Centro Académico de Alajuela, thus contributing to solve a deficiency evidenced during the 
process of accreditation undergone by the program by the end of 2014. It now became an easy option to replicate in other sites where IC is implemented.

From the teaching point of view, integration of the Laboratory with the IC courses and opening to the community outside campus (e.g. nearby neighborhoods or local government institutions) are two areas in which there is still work to be done. Regarding the first aspect, tests have been conducted in the courses Data Structures, Computer Architecture and Software Engineering Project, expanding the impact of the LabExp throughout the student community (see Table2). According to the professors criteria, using computer technology with limited resources -few kilobytes memory and processing capacity measurable in megahertz- offers significant educational advantages for the development of dynamics that allow the students to consolidate the basic concepts of the computer science and computer systems.

The Free Cartography Workshops offered an opportunity for the lab to participate in outreach activities involving students. This kind of activities represent an enriching educational experience that should be deeply analyzed. For students in their first year, that aren't yet prepared for getting involved in a research project, it was a highly motivating activity. The participation of women during workshops was also significant.

Participation of students and faculty in research and extension projects allowed TEC to present itself and get involved with the community of Alajuela. Students participating in the Laboratory presented their work in various activities in the campus, such as the Software Freedom Day, Open Data Day, Vocational Fairs. For the later, the presence of the LabExp was quite positive as regards to the process of attracting new students.

LabExp's research projects are developed within the framework of university formal education, resulting in a more structured work in relation to goals definition, monitoring of activities and achievement of results. At the same time, the projects offered a space to involved students where they could face new technical problems; delve into the concepts of Software Engineering; work in teamwork programming environments social skills in programming- and engage in research projects following the same research and extension topics the IC program works with. Permanent collaboration with professors made it possible to propose projects lasting two or more years and produce results focused on providing solutions to the local communities with specific needs.

The academic environment of the LabExp promoted the formulation of three research funding proposals submitted to TEC in 2015 and 2016. The purpose of these proposals is to request funds and time for the participating professors and students. Without time assigned for professors to work at the LabExp, project progress is limited, no matter their motivation, which may lead to important professor and student burnout. Likewise, limited physical space to work restricts the development of the tasks assigned.

Part of the future work is to find support to consolidate the existing projects, so that new professors and students may get involved in research projects, with time assigned for that purpose. Linking our programs with other TEC programs or other public universities will be important to allow working on multidisciplinary approaches jointly. The working methodology of the LabExp and its respective projects should be systematically documented to facilitate replication. The evaluation of the impact of the LabExp on the students should be measured with a standardized tool for comparison.

The process of dissemination of results in academic spaces has been started by means of the ILT project (see figure 3), however, this aspect should be strengthened so that the other projects present their work. A poster with the project's progress and an academic article are expected for the following year. The opening of the space to the community as a creative space similar to Hackerspace, Makerspace or Fab Labs depends on access to economic resources to purchase technology and have a physical space available.

Currently Costa Rica has a deficit of 8,000 ICT related occupations 27, Latinamerica will have a deficit of 449,000 by 201928 and the U.S.A. 488,500 by 2024 29. Investment in education is the common solution to revert this situation 30]. The experience of setting the LabExp is particularly useful for Latinamerican universities planning to open a new campus or to offer a new program on ICT related disciplines, and for institutions looking towards accreditation or willing to add enriching educational experiences and real hands-on projects for their students.

\section{References}

[1] A. Radermacher and G. Walia, "Gaps between industry expectations and the abilities of graduates," pp. 525-530, 2013. [Online]. Available: http://dx.doi.org/10.1145/2445196.2445351

[2] L. D. Feisel and A. J. Rosa, "The role of the laboratory in undergraduate engineering education," Journal of Engineering Education, vol. 94, no. 1, pp. 121-130, 2005. [Online]. Available: http://dx.doi.org/10.1002/j.2168-9830.2005.tb00833.x 
[3] N. Solntseff, "A computer science microcomputer laboratory," vol. 11, no. 1. New York, NY, USA: ACM, Jan. 1979, pp. 149-154. [Online]. Available: http://dx.doi.org/10.1145/953030.809572

[4] A. C. Weaver, "Design of a microcomputer laboratory for teaching computer science," in Proceedings of the twelfth SIGCSE technical symposium on Computer science education - SIGCSE '81, vol. XXXIII, no. 2. New York, New York, USA: ACM Press, 1981, pp. 132-137. [Online]. Available: http://dx.doi.org/10.1145/800037.800977

[5] J. Ma and J. V. Nickerson, "Hands-on, simulated, and remote laboratories: A comparative literature review," ACM Comput. Surv., vol. 38, no. 3, Sep. 2006. [Online]. Available: http://dx.doi.org/10.1145/1132960.1132961

[6] B. Mikhak, C. Lyon, T. Gorton, N. Gershenfeld, C. Mcennis, and J. Taylor, "Fab lab : An alternate model of ict for development," in Development by Design (DYD02), 2002, pp. 1-7. [Online]. Available: http://cba.mit.edu/docs/papers/02.00.mikhak.pdf

[7] M. Villegas, R. Alfaro, J. Gutierrez, and F. Garzona, "Lutec: a multidisciplinary undergraduate research program for local development of new tools and strategies for education," in IEEE International Conference on Advanced Learning Technologies, 2004. Proceedings., Aug 2004, pp. 1003-1007.

[8] M. V. Lemus and Y. L. Wan, "Learning by construction camps: a model for informal science and technology education in developing countries," pp. 998-1002, Aug 2004.

[9] U. de Planificación Institucional, "Plan Nacional de Ciencia, Tecnología e Innovación 2015-2021," Ministerio de Ciencia, Tecnología y Telecomunicaciones, Tech. Rep., 2015.

[10] G. N. Walker, "Experimentation in the computer programming lab," SIGCSE Bull., vol. 36, no. 4, pp. 69-72, Jun. 2004. [Online]. Available: http://dx.doi.org/10.1145/1041624.1041660

[11] L.-K. Soh, A. Samal, S. Person, G. Nugent, and J. Lang, "Closed laboratories with embedded instructional research design for cs1," SIGCSE Bull., vol. 37, no. 1, pp. 297-301, Feb. 2005. [Online]. Available: http://dx.doi.org/10.1145/1047124.1047448

[12] J. Kawash, A. Kuipers, L. Manzara, and R. Collier, "Undergraduate assembly language instruction sweetened with the raspberry pi," in Proceedings of the 47th ACM Technical Symposium on Computing Science Education, ser. SIGCSE '16. New York, NY, USA: ACM, 2016, pp. 498-503. [Online]. Available: http://dx.doi.org/10.1145/2839509.2844552

[13] P. Blikstein and D. Krannich, "The Makers' Movement and FabLabs in Education: Experiences, Technologies, and Research," Idc '13, pp. 613-616, 2013. [Online]. Available: http://dx.doi.org/10. $1145 / 2485760.2485884$

[14] C. K. Harnett, T. R. Tretter, and S. B. Philipp, "Hackerspaces and engineering education," pp. 1-8, Oct 2014 .

[15] R. J. Bailey, H. P. Bischof, M. Kwon, T. Miller, and R. K. Raj, "On providing successful research experiences for undergraduates," pp. T2F-1-T2F-6, Oct 2011.

[16] T. P. Way, "A Virtual Laboratory Model for Encouraging Undergraduate Research," Proceedings of the 37th SIGCSE technical symposium on Computer science education - SIGCSE '06, p. 203, 2006. [Online]. Available: http://dx.doi.org/10.1145/1121341.1121406

[17] M. Rahman, "Learning in Computer Science: Assessment and Evaluation of Undergraduate Research Experience," Proceedings Frontiers in Education 35th Annual Conference, pp. F1F-1-F1F-5, 2005. [Online]. Available: http://dx.doi.org/10.1109/FIE.2005.1612020

[18] R. K. Megalingam and Ananthakrishnan Ponnileth Rajendran, "Undergraduate research experience: A case study at ECE department of Amrita University," in 2012 Annual IEEE India Conference (INDICON). IEEE, Dec. 2012, pp. 962-967. [Online]. Available: http://dx.doi.org/10.1109/INDCON. 2012.6420756

[19] M. Butler, M. Morgan, J. Sinclair, and S. Kalvala, "Comparing international indicators of student engagement for computer science," ACM International Conference Proceeding Series, vol. 01-05-Febr, 2016. [Online]. Available: http://dx.doi.org/10.1145/2843043.2843065 
[20] M. Butler, M. Morgan, J. Sheard, K. Falkner, and A. Weerasinghe, "Initiatives to Increase Engagement in First-Year ICT," Proceedings of the 2015 ACM Conference on Innovation and Technology in Computer Science Education - ITiCSE '15, pp. 308-313, 2015. [Online]. Available: http://dx.doi.org/10.1145/2729094.2742629

[21] J. Sinclair, M. Butler, M. Morgan, and S. Kalvala, "Measures of Student Engagement in Computer Science," Proceedings of the 2015 ACM Conference on Innovation and Technology in Computer Science Education - ITiCSE '15, pp. 242-247, 2015. [Online]. Available: http://dx.doi.org/10.1145/2729094.2742586

[22] A. K. Peters, A. Berglund, A. Eckerdal, and A. Pears, "First year computer science and IT students' experience of participation in the discipline," Proceedings - 2014 International Conference on Teaching and Learning in Computing and Engineering, LATICE 2014, pp. 1-8, 2014. [Online]. Available: http://dx.doi.org/10.1109/LaTiCE.2014.9

[23] H. J. C. Ellis, G. W. Hislop, J. S. Rodriguez, and R. A. Morelli, "Student Software Engineering Learning via Participation in Humanitarian FOSS Projects," ASEE Annual Conference and Exposition, 2012.

[24] D. Reetz, "Why in DIY Book Scanning, The," NYL Sch. L. Rev., vol. 55, pp. 251-269, 2010. [Online]. Available: http://heinonlinebackup.com/hol-cgi-bin/get $\{-\}$ pdf.cgi?handle=hein.journals/ nyls $55\{\&\}$ section $=12$

[25] J. Gutiérrez Alfaro, A. Sanabria Rodríguez, D. Ugalde Ávila, D. Solís Méndez, M. Elizondo Pérez, and T. Kong Hsu, "Librescan: Software libre para la digitalización de documentos utilizando escáneres de bajo costo," in Proceedings of theXVII Workshop de Software Livre, WSL 2016, Porto Alegre, Brasil, 2016.

[26] F. Ramm, J. Topf, and S. Chilton, OpenStreetMap: Using and Enhancing the Free Map of the World. Cambridge: UIT Cambridge, 2011.

[27] K. Chacón Jiménez, "Sector tic clama para atraer la atención de los técnicos," San José, Costa Rica, 2016. [Online]. Available: http://www.elfinancierocr.com/tecnologia/ TIC-INA-Micitt-demanda-laboral-profesionales-tecnicos-Camtic\{_\}0\{_\}925707433.html

[28] IDC, "Informe técnico. destrezas en materia de redes en américa latina," Tech. Rep., 2016. [Online]. Available: http://csrinfo.cisconetspace.com/rs/059-VFZ-834/images/Cisco-Skills-Gap.pdf? pdf=Skills-Gap

[29] U. B. of Labor Statistics, "Occutation outlook handbook," 2015. [Online]. Available: https: //www.bls.gov/ooh/computer-and-information-technology/home.htm

[30] CEPAL, "Ciencia, Tecnología e Innovación en la economía digital. La situación de América Latina y el Caribe." CEPAL, Tech. Rep., 2016. [Online]. Available: http://repositorio.cepal.org/bitstream/ handle/11362/40530/3/S1600833\{_\}es.pdf 